\title{
The Politics of Repair in a Postcolonial Context: A Minor Case Study
}

\author{
CATHI HO SCHAR \\ University of Hawai'i at Mānoa
}

\author{
DANIEL S. FRIEDMAN \\ University of Hawai'i at Mānoa
}

"Repair is a political act. A repurposing of designed objects in ways that may or may not have been planned. Tools or facilities for repair are similarly political in that they can rewrite conventional beliefs about what we can change and how we can change it..."

-Daniela K. Rosner and Morgan G. Ames, "Designing for Repair? Infrastructures and Materialities of Breakdown," (CSCW '14, February 15-19, 2014, Baltimore) ${ }^{1}$

The University of Hawai'i at Mānoa is the flagship campus for the country's most remote and westernmost state. It lies over two thousand nautical miles from the nearest continent, roughly in the center of the Pacific Ocean, the largest division of the world hydrosphere. Until 1893, Hawai'i was a sovereign kingdom. In 1959, the U.S. government annexed Hawai'i as the last and newest of its fifty states. This vivid context-Pacific, Asian, Hawaiian, American, postcolonial-constitutes both a geographical and cultural orientation. In view of these numerous, vivid conditions, our paper offers a single case study based on small projects underway at Mānoa, where the senior leadership of the university invited the newly established University of Hawai'i Community Design Center to address the chronic disrepair of campus buildings and public spaces through low-cost, high-impact design interventions. The aim of these interventions is to improve perceived qualities of public space and campus character, which have suffered under the weight of the university's half-billion dollar deferred maintenance backlog. Two defining issues converge in this work: the physical and visual integrity of the campus; and campus identity and experience in a postcolonial context, framed by the expectations and entitlements of Hawai'i's indigenous community. The unexpected product of this convergence is a new approach to campus design we describe as a "repair practice." Our projects introduce alternative methodologies for campus design through scaling operations that explore the effects of wear and tear in four rectangular transects taken through key campus axes. Within these transects, we conducted inventories of the small aberrations and defects that degrade campus legibility and pride of place. Based on the analysis of these four transects and their condition, we develop a taxonomy of defects and strategically leverage repair protocols and routine maintenance as a medium for identity, wayfinding, and placemaking. In chapter 14 of the seminal A Thousand Plateaus, "1440: The Smooth and the Striated," Gilles Deleuze and Felix Guattari contrast prescientific Polynesian navigational practices with European cartography and its gridded meridians. ${ }^{2}$ Following suit, we explore these radical attributes in our own approach, e.g., we interpret indigenous space as "smooth," colonial space "striated." The following case study describes and critiques our application of these subtle distinctions in the repainting, repaving, and resurfacing of selected campus sites, inflecting public space with peripheral references to indigenous systems of wayfinding and visual nomenclature. In particular, we draw on Polynesian stick maps and the Hawaiian star compass for their ornamental content. We design these allusions to Native Hawaiian systems of representation to gently "reprogram" the surfaces and fissures of the contemporary Mānoa campus, minor but connected interventions that reside within and between indigenous and conventional Western understandings of position, direction, and orientation-between the smooth and the striated, one always tending toward the other.

\section{CONTEXT}

Our aim in this paper is to present a minor case study that describes the trajectory of small-scale design interventions currently underway on the campus of the University of Hawai'i at Mānoa. The first part of the paper will sketch the context for our project, the second part will describe the project itself and our work to date. The cultural context of this work radically conditions the theories, practices, and methods we seek to apply, starting with the location of our site: the 320-acre University of Hawai'i flagship campus, in the prominent Honolulu neighborhood of Mānoa, which occupies a broad valley spilling seaward from the base of O'ahu's volcanic Ko'olau range, one mile north-northeast of Waikiki and the downtown recreational waterfront.

Between 1795 and 1893, the Hawaiian islands constituted a single sovereign kingdom. In 1893, the Chicago World's Columbian Exposition opened in celebration of the 400th anniversary of Columbus's discovery of the "New World"; in that same year, a coalition of armed businessmen opposed to constitutional reform overthrew Queen Lili'uokalani, ending the monarchy. It is difficult if not impossible to practice 

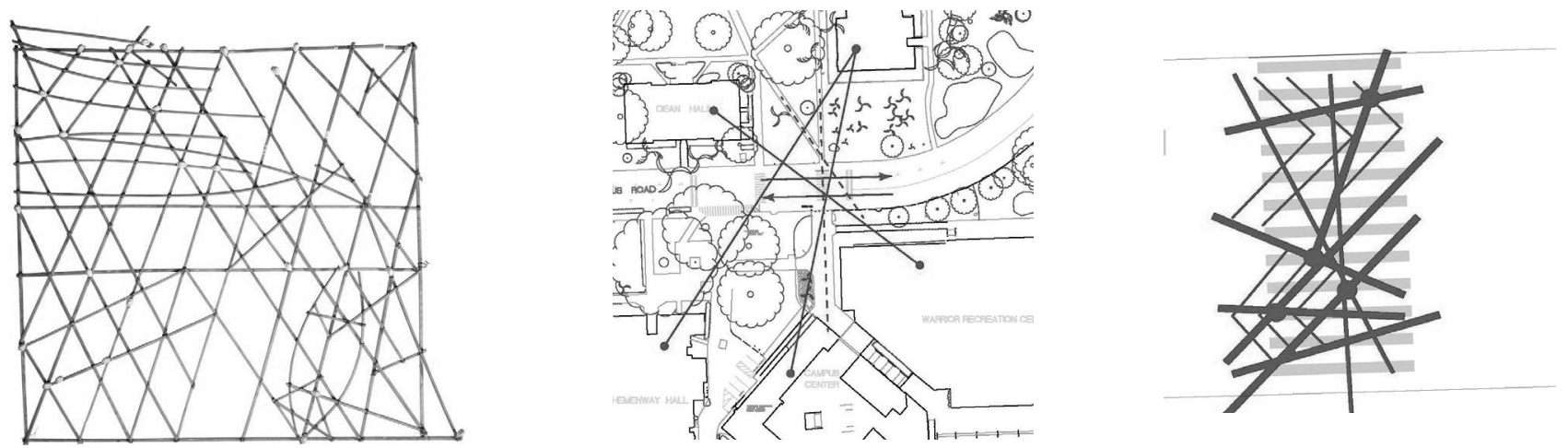

Figure 1: Polynesian stick map; campus network; crosswalk sketch.

architecture or any profession in Hawai'i without encountering the political and cultural repercussions of annexation. Contemporary Hawaii's legislature, judiciary, economy, educational system, municipal governments, and public policies still engage persistent tension between the host culture and other cultures and ethnicities that have settled in this region since 1800, drawn to its temperate subtropical climate and related agricultural assets.

Pearl Harbor and post-War tourism have shaped the contemporary perception of Hawaii-the USS Arizona memorial, surfing, hula, shaved ice (popularized by the Hawai'i-born 44th U.S. president, Barack Obama)-generally obscuring the fact that the state serves as headquarters for the U.S. Indo-Pacific Command, whose mission covers 52 percent of the planet, comprising 36 nations, more than half the world's population (over 3000 languages), and 5 of 7 U.S. defense treaties. Of 375,000 personnel serving USINDOPACOM, Hawai'i houses roughly 50,000 troops, girded by the fourth largest military workforce in the country. ${ }^{3}$ It would not be going too far to say that the experience of Native Hawaiians corresponds with Frantz Fanon's argument, in The Wretched of the Earth, that "colonial subjects suffer not just from material indignities and humiliation, but also, more painfully and perversely, from an internalized inferiority, which Fanon believed only violence could dismantle "4

The contemporary Native Hawaiian ethos has its roots in Hawaiian cosmology, adapted by King Kamehameha I following his hard-fought unification of island tribes in the late 18th century. Kamehameha I oversaw the transformation of the archipelago's tribal warrior culture into structures of rule characterized by increasing civility, tolerance for strangers, and basic human rights, evolving into the widely misunderstood but thriving philosophy of "aloha." 'Aloha is a not a salutation, not merely a synonym for "love," and not just a residue of antiquated indigenous practices; rather, it is principle embedded in the legal systems of the state. Section 5-7.5 of the Hawai' $i$ Revised Statutes contains express, non-trivial references to the indigenous values underlying for public service and all public institutions in the state:
- 'AAloha Spirit' is the coordination of mind and heart within each person. It brings each person to the self. Each person must think and emote good feelings to others. In the contemplation and presence of the life force, "'Aloha," the following unuhi laula loa may be used:

- "Akahai," meaning kindness to be expressed with tenderness;

- "Lokahi," meaning unity, to be expressed with harmony;

- "Oluolu," meaning agreeable, to be expressed with pleasantness;

- "'Haahaa," meaning humility, to be expressed with modesty;

- "'Ahonui," meaning patience, to be expressed with perseverance.

These are traits of character that express the charm, warmth and sincerity of Hawai'i's people. It was the working philosophy of native Hawaiians and was presented as a gift to the people of Hawai'i. 'Aloha is more than a word of greeting or farewell or a salutation. 'Aloha means mutual regard and affection and extends warmth in caring with no obligation in return. 'Aloha is the essence of relationships in which each person is important to every other person for collective existence. 'Aloha means to hear what is not said, to see what cannot be seen and to know the unknowable.

In exercising their power on behalf of the people and in fulfillment of their responsibilities, obligations and service to the people, the legislature, governor, lieutenant governor, executive officers of each department, the chief justice, associate justices, and judges of the appellate, circuit, and district courts may contemplate and reside with the life force and give consideration to the "'Aloha Spirit." [L 1986, c 202, §1]

By extension, "'aloha 'āina" ("love of the land") describes a complex, cultural system that connects territory, water, sustenance, and social structure within a fluid cosmology characterized by reverence for nature and community, which it views as genealogically intertwined. "'Āina is often simply 


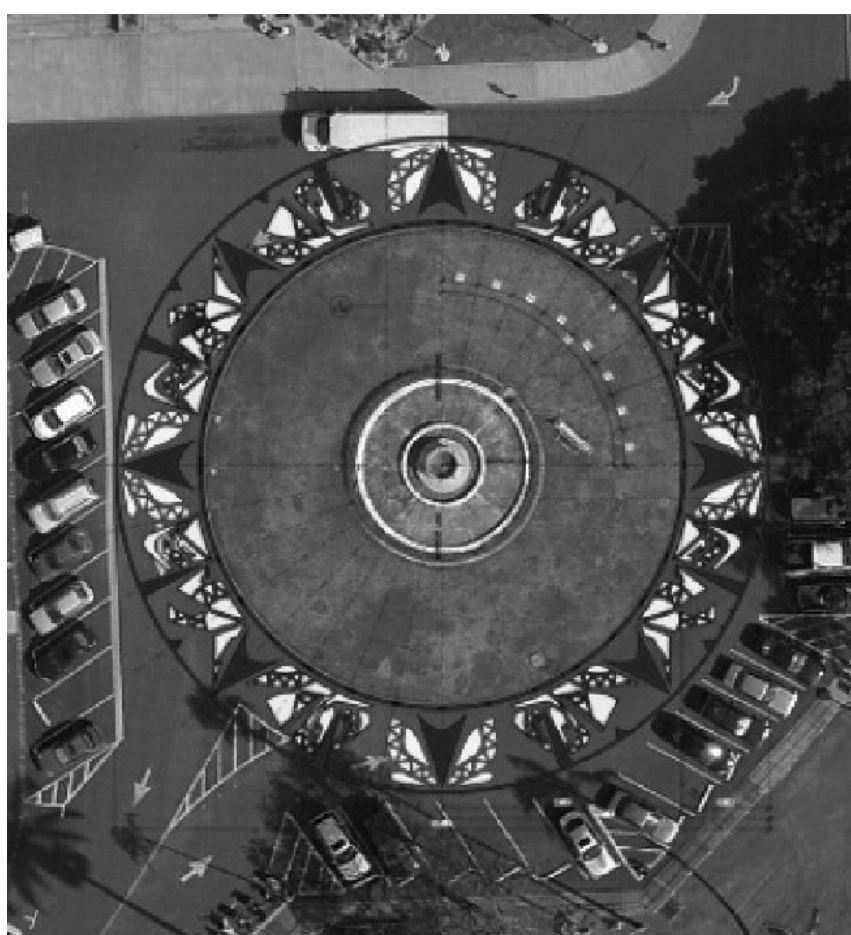

Figure 2: The proposed Varney Circle compass rose, a work-in-progress.

translated as land," writes Kelsy M.Y. Jorgensen, Hawaiian Studies major and SOA graduate research assistant, "but a look at its linguistic roots shows nuanced spiritual, ethical, and intellectual implications that go beyond a Western concept of land." 6 UHM Hawai'inuiākea School of Hawaiian Knowledge dean Jon Osorio elaborates: "'Aloha 'āina is a relationship not just with the land but really with nature itself, and in particular that part of the land and sea and streams and water that actually sustains life." 'Āina is the ancient, central, philosophical, ethical, and cultural locus of the Hawaiian worldview, and therefore a fundamental element of our approach to micro-interventions at Mānoa. Likewise, 'aloha 'aina still permeates the discourse on design, land use, and development in contemporary Honolulu, despite the fact that most contemporary commercial architecture and urban design ignore its principles.

To the extent our small campus project has a theoretical framework, then, it hybridizes indigenous ethics with two currents of late twentieth century philosophy: Gianni Vattimo's "weak thought" (il pensiero debole), the aim of which is to recollect, interpret, and twist traces of linguistic tradition in service to an "ethics of weakness" and non-aggression; ${ }^{8}$ and Deleuze's and Guattari's aforementioned distinction, in A Thousand Plateaus, between smooth and striated space, which explores the intertwining and transformation of rational, 'colonial' epistemologies (such as weaving, surveying, and cartography) with embodied, 'indigenous' epistemologies (such as felt, quilting, and ancient Polynesian maritime navigation). Weaving is "necessarily delimited, closed on at least one side," they write, ." . . limited by the frame of the warp ... [implying] a closed space"; felt, on the other hand, is smooth, "in principle infinite, open, and unlimited in every direction; it has neither top nor bottom nor center; it does not assign fixed or mobile elements but distributes a continuous variation." ${ }^{\prime 9}$ Further to their analysis of the textile properties of spatial hybridity, Deleuze and Guattari describe a quilt as "an amorphous collection of juxtaposed pieces that can be joined together in an infinite number of ways. It is as if a smooth space emanated, sprang from a striated space, but not without a correlation between the two, a recapitulation of one in the other, a furtherance of one through the other. Yet the complex difference persists." ${ }^{10}$ Central to Polynesian navigation is the stick map, which helped guide mariners from Tahiti to Hawai'i roughly a thousand years ago. Stick maps embody smooth space, in contrast to the European astrolabe (from the Greek astrolabos, "star-taking") and the sextant (from the Latin sextans, "sixth part"), which striate the open sea with meridians and parallels transposed onto maps, expressed as "bearings."11

Despite a sublime natural setting, the flagship campus of the University of Hawai' $i$ is in rough shape. It suffers from chronic budget constraints that preclude major capital development and renovation, also from aging infrastructure, outmoded buildings, and a gargantuan deferred maintenance backlog. At the initial instigation of the university's academic deans, UHCDC approached the system administration with a proposal for a major campus visioning exercise based on conventional design-driven master-planning practices. The UH System vice president for administration rejected the ideaa: "Why should I ask the regents for fifty thousand dollars to make beautiful pictures of a campus we can't afford when I don't have enough money to fix the leaky ceiling in the office of our CFO?"

After consultation with facilities and space planning managers, UHCDC proposed an alternative approach based on the aforementioned theoretical framework. The new approach cobbled together a methodology from pop-up, guerilla, and tactical urbanism - provisional, temporary, and distributive interventions-QLC ("quick, light, cheap"), lots of small bets amounting to big impacts. This proposal led to an exercise undertaken in the Fall, 2016, by students enrolled in our graduate curriculum's required professional practice course: inventory ugly and dysfunctional campus spaces; explore hybrid methodologies; and develop alternative design scenarios. Following the presentation of course outcomes to the university's academic leadership, the university chancellor allocated $\$ 500 \mathrm{~K}$ to support proof of concept design-build installations, which we have gathered up under the general title "UHM Transect Study," "Transect" for short. 


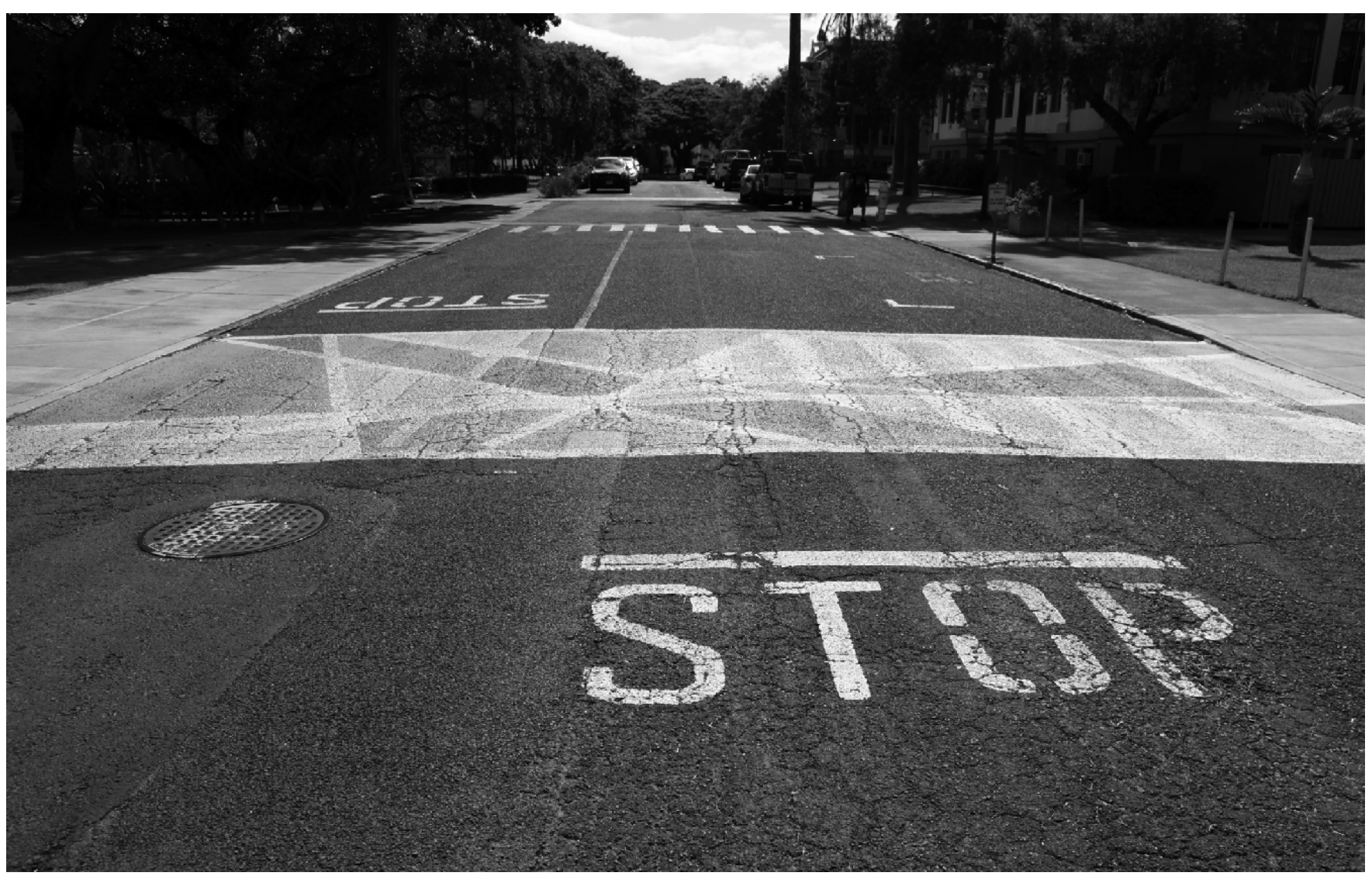

Figure 3: Completed campus crosswalk incorporating directional axes based on the Polynesian stick map.

\section{APPLIED PRINCIPLES}

The Transect project began with disrepair, revisiting Mostafavi and Leatherbarrow's On Weathering, which explores the continued transformation of buildings over time, and which finds significance in natural processes resulting from continuous exposure to the elements, use, and aging, facts that are everchanging and that "[inhere] in all construction." ${ }^{12}$ What we take from this is the authors' attention to the aging process, a force as sure as gravity, but one that receives much less consideration. While Mostafavi and Leatherbarrow stop short of material degradation, this project extends their examination into the cycles of disrepair and repair that in concert shape the life of a building.

Architect Hilary Sample likewise foregrounds problems of wear and tear in her book Maintenance Architecture, pointing out works like Gordon Matta Clark's "Manifesto for Maintenance Art" (1969), that understood the relevance of maintenance in art and life a half century ago. Sample writes, "Maintenance is much more than a metaphor for rethinking culture and society; it exposes a range of imperfections, from unmaking - the decay of buildings, failing joints, or chipped glass - to social inequities and unjust labor practices, and to tangible acts that lead to novel design thinking, formal invention, and unprecedented detailing." ${ }^{13}$
While Sample's argument is congenial to our perspective on repair, the architectural case studies that she describes feature mechanized, self-cleaning building technologies that aim to be "maintenance free," but they barely live up to the call for rethinking culture, society, and patterns of consumption. Perhaps this comes from the distinction between maintenance and repair. "Maintenance" is synonymous with perpetuation, upkeep, preservation, and conservation, and suggests little that has to do with change. On the other hand, "repair" means to fix, put back together, piece together, sew (up), stitch, dam, patch, cobble, rehabilitate, renew, renovate, put right or set right, set straight, straighten out, sort out, rectify, remedy, cure, resolve, square, settle, correct, retrieve, improve, make better, a word far more apt to describe a context for social and cultural rethinking and design inquiry. An essential synonym of "repair" is arguably "mend," a shortened version of the word "amend," meaning "to make fairer, more accurate, or more up-to-date; modify formally; make better; improve"; mend derives from the Latin emendare, from e-, 'out of', plus menda, 'a fault'. ${ }^{14}$

In closer alignment with our project are new trends in product design that approach the problem of repair differently. Recent developments at this scale integrate repair firmly into a product's original form, material, engineering, and policy, resulting in changes that affect manufacturing and 
production. Designers embed repairability in a product at the front end, anticipating future breakage and repair protocols. These repair protocols consider the instructions, data, parts, and skill sets of consumers, equipping them to perform their own repairs. For example, the outdoor clothing and gear company Patagonia designed a repairable zipper and launched a program called "Worn Wear" that not only provides repair instructions for its products, but also recommends steps for end-of-use recycling. Patagonia is just one of many companies integrating repair and re-use into their brand identity and basic business model. The concept of a repair practice integrates the unavoidable and continuous task of repairing that occurs throughout the lifespan of product with a critical examination of objectives, choices, and solutions. These novel repair practices draw from collaborative expertise and user-based problem-solving. Similar practices have grown, producing a business niche for "fixperts" and "fixit" clinics, that provide or return agency to the end user. This transfer of agency is especially relevant to our project on campus. ${ }^{15}$

Our Transect project takes this idea of a repair practice led by student "fixperts" and builds off of the success of tactical urbanism, urban acupuncture, trickle-up urbanism, DIY design, pop-up design, and the myriad other terminologies that describe small, temporal, low-cost, low-tech, bottomup design efforts that have been used to transform urban space and life. At the 2012 Venice Architecture Biennale, the US Pavilion showcased these types of projects in an exhibition called Spontaneous Interventions: Design Action for the Common Good. The exhibit highlighted the impact of provisional and participatory problem-driven design. Diverse projects visualized the combination of repair and design throughout this body of work. In our case, the unanticipated impact of the Transect project eventually earned $\$ 500 \mathrm{~K}$ in funding and led to the evolution of the project from a course exercise exploring small-scale, bottom-up, tactical interventions to a top-down, centralized, experimental approach to campus disrepair. The project's trajectory provides evidence that "spontaneous interventions" can coalesce into something larger than the sum of their parts.

\section{PROJECT METHODOLOGY}

The project that initiated this case study began as a 3-credit professional practice course, involving twenty-four students in four groups acting as "firms." The instructor asked students to catalog campus problems that included unkempt infrastructure, identity, visual disconsonance, and chronic disrepair through "light cheap quick" solutions. Students identified four significant transects-large, rectangular cross sections of campus tissue-capturing areas of the campus with high pedestrian traffic and designated as zones of analysis and intervention. These transects included two iconic axes within the campus, Legacy Path and McCarthy Mall, and two external axes that define the approach and entry to the campus along University Avenue. Assigned to one of four transects, student groups were asked to identify and inventory the condition of the campus emphasizing four categories: thresholds, corridors, surfaces, and ugly objects. These inventories cataloged broken curbs, cracked sidewalks, crumbling pavement, dark entries, illegible circulation, and the proliferation of utility equipment, bollards, and temporary barricades that litter the campus.

Next, student teams identified "micro-sites" most amenable to this type of work, then proposed and visualized simple design remedies adapting techniques from tactical urbanism, focusing on sidewalks, roads, building faces, and urban amenities. They developed and rendered a series of low-cost, remedial repair palettes including paint schedules, color schemes, material finishes, supergraphics, and urban accessories, including crosswalks, screens, landscaping, utility boxes, and stenciled surfaces, among other ideas. Their work eventually attracted the attention of university deans, who had been grappling with problems of recruitment and retention, which in turn led the chancellor to allocate $\$ 500 \mathrm{~K}$ to the project to support proof of concept prototypes. Strategically, this funding addressed university-wide frustration with the slow pace of capital improvements, and signaled official support for cheaper alternatives at a smaller but more nimble scale, to test their impact on campus experience and perception.

As a centrally supported repair practice, it was important to develop schemes that provide cohesion among the various elements of this portfolio of small projects. We therefore proposed a framework to align with long-range campus strategies that promote "a Hawaiian place of learning," central to the concept of an indigenous-serving and multi-cultural institution and laboratory for island sustainability. We applied this mission and vision to the functional objectives of the initiative, which we defined along a spectrum of needs between wayfinding and placemaking. The administration prioritized wayfinding as one of the biggest problems on campus: people are lost and don't know where to go. Likewise, the project prioritized identity and need to appropriately acknowledge the campus's indigenous-serving, postcolonial, multicultural, student-centered, and sustainability-focused mission.

The first micro-project to be implemented involved the repainting of a series of large, circular planter benches suffering from the kind of uninspiring, unsightly brown color that repels gathering. This small bet paid off: strategically repainting the benches with a brighter palette of colors provided the first evidence that our approach could make a difference. The project began with members of the maintenance staff expressing skepticism and indifference; they seemed to regard our painting strategy as inconvenient, frivolous work. When they repainted the benches, they liked the result, which changed their predispositions and transformed the crew into allies and stakeholders. They agreed that these changes made the campus look better. Their gradual acceptance of 
the benefits of our work was an unexpected metric for the project. Central to this win-win is our increasing sensitivity to relations with the university maintenance staff, indespensible partners in this repair practice; respect for their effort is essential. When we were able to provide additional value to their work, the true economy and potential of repair practice came to light, embodied in their positive response.

The first real design proposal to be developed and implemented was the painting of two crosswalks near the Campus Center. The students in the professional practice course visualized different graphic crosswalk patterns based on Hawaiian cultural motifs. As the design developed within the framework, students reconceptualized the crosswalk as an environmental wayfinding problem with the added function of orienting students to position and direction. The Polynesian stick map, which charts ocean currents, wave aberrations, and land masses relative to a given position, provided inspiration. The final crosswalk design traces the vectors of major circulation paths and connections between campus destination points. Each crosswalk serves as a place-based custom mapping of the campus at a given location.

The crosswalks provided a suitable context for a repair practice, since they require repainting every 18 months as part of regular roadway maintenance. The crosswalk markings consist of typical 4-inch white painted lines. We covered the spaces between the lines with shades of ordinary green traffic paint. Crews painted each crosswalk in two days over two weekends. Without being anything more than a different configuration of paint on pavement, the crosswalks continue to provide small nodes of color and vitality that amplify campus identity through the novel design of commonplace function.

We used the crosswalks as a test case for a much larger roadway graphic proposed for Varney Circle, a roundabout encircling a broken fountain constructed in the 1930s at the crossroads of two major campus axes, part of the original campus plan. Despite this prominent location, the roundabout and fountain represent conspicuous levels of disrepair, pedestrian and automobile conflict, and missed opportunities for a true campus focal point. Consistent with the design of the crosswalks, the 16-foot-wide pavement graphic for the asphalt road around the circle engages the area as an orientational node for the campus, consolidating cardinal and indigenous wayfinding indicators into a 60-foot diameter design based on the Hawaiian navigational star compass developed by the contemporary Polynesian navigator and Nainoa Thompson, president of the Polynesian Voyaging Society, one of the first modern mariners to employ traditional Polynesian navigational arts since the 14th century-smooth-becoming-striated-becoming-smooth. Like the crosswalks, the environmental graphic is tactically derivative, respectful of both native and local means of orienting to place.

Three other projects remain in progress. The first continues with paint, involving the strategic, incremental repainting of select building details to refresh the campus. The project explores both ancient and contemporary color systems, providing a hybrid reference for decision-making. Old and new paint work together as the interim campus palette and accept the slow process of large-scale change through small-scale repair. At the invitation of the university administration, we have also undertaken a wayfinding study that explores both digital and analog campus wayfinding solutions. A third project addresses yet another campus eyesore: residual piping from a demolished engineering building and decommissioned irrigation cistern, located on one side of the most populated student site on campus, directly adjacent to the university's new Warrior Recreation Center, a state-of-the art fitness and indoor sports facility. The proposal features an umbrellacovered 55-foot long, recycled, precast concrete, outdoor "kitchen" table, situated along one edge of the courtyard at the base of university's student center. This project remains in the approval stage; interestingly, it has encountered the most resistance, as the only project that represents new construction moreso than a new approach to maintenance and repair.

\section{CONCLUSION}

While the life of a building includes design, construction, operations and maintenance (O\&M), repair, decay, disuse, and demolition, architectural pedagogy and practice focus primarily on design and construction. Although the professional curricula occasionally incorporates O\&M and deconstruction into life cycle or "cradle-to-cradle" considerations, NAAB student performance criteria largely ignore the topic of repair and maintenance. This paper argues that repair can be a critical practice-distinct from renovation, adaptive reuse, and preservation, most of which operate within the usual telos of design, subscribing to Viollet-le-Duc's assertion that "to restore a building is not to repair it, nor to do maintenance, nor to rebuild it, it is to re-establish it in an ultimate state that never before existed."

Repair as critical practice offers an alternative ethic that both transforms and multiplies the value of what already exists without seeking to overpower it, instead offering social, environmental, economic, and cultural benefits while fitting into a schema ordinarily typecast as routine. This notion of a repair practice challenges the assumption that restoration constitutes a return to an original or even superior condition, and advocates for the continuous renegotiation of the lifecycle and meaning of buildings and environments and their material appearance and composition. In this case study, renegotiation 
offers the university an opportunity to integrate the changing social, cultural, and ecological context through the repair and maintenance of the campus, empowering students, faculty, and administrators to drive this continual process forward, admitting (even celebrating) its unavoidable imperfections.

\section{ENDNOTES}

1. Daniela K. Rosner and Morgan G. Ames, "Designing for Repair? Infrastructures and Materialities of Breakdown," (CSCW '14, February 15-19, 2014, Baltimore), n.p.

2. Gilles Deleuze and Felix Guattari, "1440: The Smooth and the Striated," in A Thousand Plateaus: Capitalism and Schizophrenia, trans. Brian Massumi
(Minneapolis: University of Minnesota Press, 1987), 482; 474-500.

3. http://www.pacom.mil/About-USINDOPACOM/USPACOM-Area-ofResponsibility/ [accessed June 30, 2018].

4. Alice Gregory, "Unbreakable: The Fearless Cinema of Claire Denis," in The New Yorker (May 28, 2018), 34

5. https://portal.ehawaii.gov/government/hawaii-legislature/hawaii-revisedstatutes/ [accessed June 30, 2018].

6. Kelsy M. Y. Jorgenson, E Ho ' $\mathrm{i}$ Ka U'i: Perspectives on Placemaking in Hawai'i, manuscript, 36.

7. Jon Osorio, interview with Julia Steele, Hawaii Public Radio (February 5 2016), http://www.hawaiipublicradio.org/people/julia-steele [accessed June 30, 2018].

8. Peter Carravetta, "What is Weak Thought? The Original Thesis and Context of il pesiero debole," in Gianni Vattimo and Pier Aldo Rovatti, eds., Weak Thought (Albany: State University of New York Press, 2012), 7, 27; see also in the same volume Gianni Vattimo, "Dialects, Difference, Weak Thought," 39-52; and Gianni Vattimo, The End of Modernity: Nihilism and Hermeneutics in Postmodern Culture, trans. Jon R. Snyder (Baltimore: The Johns Hopkins University Press, 1985, 79-89.

9. Deleuze and Guattari, 475 .

10. Ibid., 477

11. Ibid., 479

12. Mohsen Mostafavi and David Leatherbarrow, Weathering: The Life of Buildings in Time (Cambridge, MA: The MIT Press, 1993), 116.

13. Hillary Sample, Maintenance Architecture (Cambridge: The MIT Press, 2016), 20.

14. Oxford English Dictionary (2018), s.v. "maintenance," "repair," "mend," "amend," and "emend.

15. Rosner and Ames, n.p.

16. Quoted in Sample, 20. 